\title{
PRESENÇA E AFETO NA EXPERIÊNCIA DO ENCONTRO NA ARTE: QUANDO NÃO SE PODEM PREVER SEUS EFEITOS
}

PRESENCE AND AFFECT OF THE ENCOUNTER EXPERIENCE IN ART: WHEN ITS EFFECTS ARE NOT ANTICIPATED

LA PRESENCIA Y EL AFECTO EN LA EXPERIENCIA DEL ENCUENTRO EN EL ARTE: CUANDO SUS EFECTOS NO SON PREVISTOS

\section{Milene Lopes Duenha}




\section{Resumo}

Como a arte da presença pode produzir afetos com seus meios e efetivar-se como potência nos encontros entre corpos na contemporaneidade? Este ensaio se destina a uma discussão sobre a produção e recepção nas artes presenciais, destacando uma noção de presença do artista como relação, e de arte como potência intensiva capaz de provocar fissuras perceptivas. Por meio de uma abordagem fenomenológica convida à observação das alterações nos modos de produção, leitura e interlocução na experiência artística, com base em teorias de Bento Espinosa, Flávio Desgranges, José Gil, Erika Fischer-Lichte entre outros.

Palavras-chave: Artes da presença, Recepção, Relação.

\section{Abstract}

How can the art of presence produce affect with its manners and become effective on the encounters among bodies in the contemporary world? This essay aims to discuss the production and reception in the arts of presence, highlighting the presence of the artist as a relation with the site, and art as an intensive power capable of causing perceptible cracks. Through a phenomenological approach, this study is an to observe the changes in production, reading an interlocution methods, in artistic experience, based on theories by Benedict Spinoza, Flavio Desgranges, José Gil, Erika Fischer-Lichte and others.

Keywords: Art of presence, Reception, Relation.

\section{Resumen}

¿Cómo el arte de la presencia puede producir afectos con sus procedimientos y ser eficaz en los encuentros entre los cuerpos en el mundo contemporáneo? Este ensayo plantea un debate sobre la producción y recepción en arte de presencia, destacando un sentido de la presencia del artista como relación, y del arte como potencia intensiva capaz de causar grietas perceptivas. Mediante un enfoque fenomenológico se invita a la observación de los cambios en los métodos de producción, lectura e interlocución en la experiencia artística, basada en las teorías de Benedicto Spinoza, Flavio Desgranges, José Gil, Erika Fischer-Lichte, entre otros.

Palabras clave: Arte de presencia, Recepción, Relación. 
A partir da primeira metade do século XX, o termo "presença" passou a ser recorrente nas proposições artísticas que envolvem a relação entre artista e público no aqui-agora. Os procedimentos nas artes presenciais, principalmente no teatro, passam a incluir questões como a capacidade do artista de capturar a atenção do público, a abertura ao ambiente, e a compreensão do interlocutor como componente ativo da relação presencial. Com as consequentes alterações no modo de produção e recepção da arte ao longo dos séculos $X X$ e $X X I$, e de acordo com as alterações dos modos de vida em sociedade, a arte ganha novas questões, exigentes de novas ferramentas conceituais. O pesquisador teatral brasileiro Flávio Desgranges (2012) trata das alterações na percepção da arte diante das mudanças na sociedade em diferentes momentos da história, observando que, perante tais alterações, já não seria possível uma previsibilidade acerca da recepção da arte na contemporaneidade.

Já no início do século XX, com o advento da redescoberta do corpo no teatro, devido à descentralização do texto dramático, e a exemplo de práticas como as de Constantin Stanislavski, Antonin Artaud e Vsevolod Emilevitch Meyerhold, se observa uma produção cada vez mais voltada aos aspectos sensoriais das relações, como nos traz o pesquisador teatral italiano Marco De Marinis (2005). Tais alterações nos modos de produção teatral aparecem também como forma de contraposição ao comportamento do sujeito moderno, que estaria ligado à lógica de funcionamento da própria sociedade na qual ele precisaria ser eficiente, rápido, sempre alerta, seguindo o imperativo da produtividade, e com isso ficaria automatizado, assim como a máquina por ele operada. Esse estado de alerta, e a operação por uma "razão instrumental" criariam um modo anestesiado de percepção, em "um padrão superficial da consciência" (DESGRANGES, 2012, p. 125). Sua capacidade de imaginação e seus sentimentos estariam sufocados, como nos traz Desgranges. Diante disso, uma recepção tátil, essa que nos provoca os sentidos, pareceria conveniente, convidando o interlocutor à produção de outros "sentidos" possíveis na arte e na vida. (Qualquer semelhança com a estrutura social na atualidade não passa de mera manutenção de sistemas fundamentados na noção de produtividade e lucro).

Com uma produção teatral menos voltada à linearidade de uma dramaturgia escrita, o herói e a história unidimensional começam a ser desintegra- 
dos na primeira metade do século XX, dando vazão ao que há de tangibilidade do encontro para convidar o interlocutor a se perceber no ato de perceber 0 que acontece diante dele (Ibid). Podemos observar a ampliação da noção de dramaturgia a partir de pesquisas como as de Stanislavski, Artaud, Meyerhold e Berthold Brecht, por exemplo, que apresentam o entrelaçamento de elementos que compõe o ambiente, tais como a luz, o figurino, o cenário, o som, o público, o ambiente externo à cena. A linha dramatúrgica passaria, a partir disso, a ser organizada por cada um da plateia com o desenvolvimento de esquemas abertos de composição que convocam o espectador à ação. Daí a "provocação" de diferentes modos perceptivos - "eu faço a minha tessitura, meu conjunto de relações", como nos traz Desgranges (2012). Nesse contexto, perde-se o conforto da apresentação de uma articulação de significados prévios, da representação fixa das coisas, de modo que se possam apreender sentidos consensualmente, dando lugar à articulação individualizada de sentidos a partir dos afetos que incorrem diferentemente em cada um, e da percepção desses afetos. O teatro parece aproximar-se, cada vez mais, de elementos compositivos da dança, que passaria também por um percurso de busca por uma significação do gesto para, mais adiante, assumir-se como produtora de sentidos, como o filósofo José Gil (2001) nos apresenta, e que também será um tema abordado no decurso desse texto.

Para darmos visibilidade a esses novos entendimentos acerca da recepção da arte, a compreensão de algumas ferramentas conceituais parece necessária, e entre elas está a noção de afeto, trazida pelo filósofo holandês Bento Espinosa no livro Ética (1992), amplamente utilizada pelo filósofo francês Gilles Deleuze (2009), e por José Gil (2001). A proposição espinosista de afeto (affectus) o traz como efeito que emerge do encontro entre os corpos. Segundo Espinosa (1992), há uma constante mudança do corpo diante dos encontros, o que poderia aumentar ou diminuir sua potência de agir. Para o autor, há um esforço inerente à existência para conservar sua natureza, o que é chamado de conatus, mas há também os efeitos dos encontros que não são passíveis de previsão, tornando a interferência de um corpo sobre outro algo pouco controlável.

Espinosa (1992) afirma que os corpos não se relacionam de maneira preestabelecida. Existe, nesse contexto, a ação - que são as minhas von- 
tades; e a paixão - que são as vontades que não vêm de mim. Assim, há o resultado dos encontros entre os corpos, apresentado inicialmente pelo filósofo como bons e maus afetos, como alegria e tristeza, por exemplo, e identificá-los seria um modo de percepção imediata do que se imprimiu no corpo durante o encontro. Tal possibilidade estaria inerente ao ato de raciocinar, na tentativa de compreender o que acontece ao corpo, e de explicar os afetos, o que é denominado por Espinosa como paixões ativas. Portanto, por mais que os afetos possam ser imprevisíveis, e que não seja possível ter consciência de todos os afetos que incorrem em um encontro, conforme nos esclarece o autor, é possível compreender as impressões dos afetos no corpo ao reconhecê-los ${ }^{1}$.

Nesse contexto, a noção de afeto pode ser compreendida na arte como potência intensiva, assim como o traz Deleuze (2009), capaz de provocar transformações nos corpos, e esse processo poderia ocorrer tanto por meio de uma articulação de significados prévios, quanto pela emergência de sentidos outros, que nem sempre estariam vinculados a uma ideia de entendimento, de compreensão por uma consciência vígil, daquilo que se estaria vivenciando.

\section{Menos representação e mais tangibilidade como pos- sibilidade de emergência de novos sentidos}

Ao longo dos séculos XX e XXI, outros parâmetros para produção artística e sua recepção começam a se delinear, o que pode ser percebido mais claramente em produções contemporâneas nas artes da presença que se voltam aos aspectos performativos, a exemplo de práticas como as das companhias belgas "Need Company"2 e "Peeping Tom"3, da companhia tcheca "Farm in the

1. Esse assunto é ampliado em minha dissertação de mestrado, intitulada Presença e $(\mathrm{m})$ relação: a potência de afeto no entre corpos (DUENHA, 2014).

2. Informações sobre essa companhia podem ser encontradas em: <http://www.needcompany.org/EN>.

3. Informações sobre essa companhia podem ser encontradas em: <http://www.peepingtom. be/en>. 
cave" e da brasileira "Cena 11" Cia de dança ${ }^{5}$. Uma característica recorrente em práticas artísticas presenciais como as das companhias citadas é o fato de seus espetáculos não "representarem" a vida, mas a apresentarem como corpos em ação, assumindo proposições que lidam com a emergência de sensações, de vetores perceptivos, no aqui-agora do encontro. Por mais que aspectos de significação sejam articulados nesse processo, há um explícito convite a um engajamento sensorial diante daquilo que o próprio artista vivencia por meio da dança, de palavras desconexas, de histórias fragmentadas.

A pesquisadora teatral alemã, Erika Fischer-Lichte (2011) convida a olhar a experiência artística presencial com menos intermédio da representação (com produção e interpretação de significados), menos sujeita à semiótica, e mais próxima de uma tangibilidade das presenças. Essa discussão não se evidencia somente no campo da arte: o linguista alemão Hans Ulrich Gumbrecht (2010) também pleiteia por uma relação com as coisas do mundo sem o protagonismo do significado, pois, segundo esse autor, ao tentarmos interpretar o que as coisas significam, nós nos afastamos do que as coisas são de fato. Esse império do significado teria nos ensinado a operar por uma lógica de encaixe "racionalista", que encerra a realidade em uma coerência específica, e que permite que as emoções emerjam a partir de uma articulação desses prévios. Ao voltarmos atenção à recepção nas artes presenciais contemporâneas, colapsar significados prévios aparece como uma ação inerente ao seu processo de produção.

O pesquisador inglês Simon O'Sullivan (2011, p. 17) observa que a função da arte estaria em "mudar nosso registro intensivo, reconectar-nos com o mundo". Se considerarmos que uma das principais características da experiência artística é a possibilidade de alteração do nosso modo de perceber o mundo, e de nos percebermos nele, a consideração dos possíveis efeitos na experiência artística presencial menos vinculada a estruturas fixas de significados - que cerceiam as possibilidades de invenção de mundo -, parece pertinente. $\mathrm{Na}$ arte, a subversão de convenções preestabelecidas pode ser

4. Informações sobre essa companhia podem ser encontradas em: <http://infarma.info/enlng/profil-en>.

5. Informações sobre essa companhia podem ser encontradas em: <http://www.cena11. com.br>. 
também uma possibilidade relacional que convida a inventar novos caminhos.

E se o mundo fosse inventado por nós ao mesmo tempo em que nos inventamos nele, em vez de vivermos interpretando o que as coisas significam, solucionando problemas de um mundo criado na genialidade de um ou outro ser dotado de sabedoria o qual se deve reverenciar? Invenção e criação são diferentes, como afirma a pesquisadora brasileira Virgínia Kastrup (2004; 2014), para a qual a criação estaria mais voltada à resolução de problemas, e a invenção, não se restringiria somente a isso, mas também à sua invenção, ou seja, sem o guia: "como decifrar o que vivo", entramos em certo colapso e nos obrigamos a inventar caminhos. Sem um guia de leitura da produção artística, sem a história linear, por exemplo, somos obrigados a inventar os caminhos, a tomar decisões no ato da recepção (DESGRANGES, 2012), e nos responsabilizarmos por elas.

Uma produção artística que se baseia na articulação de significados prévios, no que há de consensual, pode, sim, carregar potência de afeto, e tem a característica de dar chaves de acesso, de deixar claro do que trata a proposição. Porém, isso não bastaria se a intenção consistisse em, de fato, criar caminhos para estimular possibilidades inventivas no interlocutor. À arte caberia a incumbência de fazer o convite, de dizer a que veio, mas também de dar-se ao estranhamento, captar os fluxos e subvertê-los em favor da invenção, ao assumir sua existência em um terreno movediço que a desafia constantemente.

\section{Potência de afeto como eficácia na sua imprevisibilidade}

A previsão sobre o que pode ou não afetar o espectador na experiência artística seria, ainda, um elemento de operação a ser considerado nas práticas contemporâneas da arte da presença? Como seria possível uma articulação de potências poéticas, em uma arte presencial, não sujeitas apenas à criação e decodificação de significados, de um modo que se considere a emergência de afetos e a construção individual de sentidos?

Vincular produção de afeto à proposição artística, reconhecendo os efeitos que um corpo ou um objeto artístico tem sobre o outro corpo, conforme observa O'Sullivan (2011, p. 17), é um movimento que se mostra contra a 
efetivação de uma abordagem transcendente do corpo e da arte, borrando limites entre o que seria representável e passível de interpretação, e o que se configura como potência em uma recepção menos sujeita a noções de significação e decodificação de informações. O afeto, nesse contexto, e baseado na acepção espinosista (ESPINOSA, 1992), estaria ligado à factualidade nas relações, ao que escapa à ideia de controle absoluto dos seus efeitos.

José Gil (2005) aborda algumas características da percepção, destinando-se a mostrar a pertinência da ideia de pequenas percepções a partir de filósofos como Gottfried Wilhelm Leibniz e Gilles Deleuze para referir-se à percepção da obra de arte. Gil distingue as fases da percepção da obra de arte, exemplificando, com a possibilidade de observação de um quadro, três regimes do olhar: O primeiro seria a percepção trivial - cognitiva - das formas, que seria uma fase de recognição e de estranheza, mas que comporta elementos familiares; A segunda seria uma percepção não trivial, a percepção de outro espaço entre as formas e outros movimentos, e entre as formas e os espaços, sugerindo a observação das estruturas não aparentes e a transição do olhar entre esses dois regimes; O terceiro seria a mudança da percepção em relação ao conjunto das formas, o que permitiria que o objeto deixasse de ser percebido objetivamente. As formas seriam inseridas em uma multiplicidade virtual aparente no deslocamento entre o nível perceptivo trivial e o não trivial. Esse terceiro nível perceptivo é descrito por Gil (2005) como estético ou artístico e, segundo o autor, possui ainda três outras características. Uma delas seria a abertura entre o trivial e o não trivial, a outra seria a possibilidade de passagem das relações não visíveis ao primeiro plano, e a terceira residiria no fato de que a percepção não comparece como uma manifestação simplesmente cognitiva ou unicamente sensorial, sendo na verdade percepção de forças. Nessa conjunção, Gil (2005) questiona de onde viria essa dupla característica da força artística, que possui modulações infinitas da força e uma singularidade relacionada a quem produziu, questionando ainda o que poderia ser uma linguagem de forças, uma vez que toda obra de arte é um reservatório delas. O filósofo consegue delinear uma teoria da recepção da arte pautada na observação de sua produção de afeto em níveis de intensidade, o que não parece oferecer outras ferramentas ao artista que não sejam considerar sua inconstância, assumir que seus efeitos não serão previsíveis. 


\section{Sobre a percepção da arte e sua produção de inten- sidades de afetos}

José Gil dedica grande parte de sua escrita à observação de que a dança que tem uma característica comum, em muitos de seus procedimentos, que é a produção de formas, imagens, vetores de sentido, sem a manutenção do compromisso com o consenso que a produção de significados encerra, assim como se observa em práticas presenciais contemporâneas que se desenvolvem sob aspectos performativos. Ao citar o trabalho de Contact Improvisation do coreógrafo Steve Paxton, Gil (2001) observa que a comunicação ${ }^{6}$, entre os corpos, no ato dessa técnica de exploração de movimento, não opera na consciência vígil, racional, mas em outro nível de consciência. O filósofo expõe essa relação como comunicação entre corpos-consciência, e a aproxima do transe para ilustrar esse acontecimento no corpo. Segundo o autor, (GIL, 2004, p. 18), "o corpo-consciência é caracterizado por uma hiperexcitabilidade, que se desenvolve sensorialmente, e também afeta os órgãos sensoriais, o que traz pequenas percepções de outros corpos que se tornam corpo-consciência". Para ele, há uma impregnação dos pensamentos pelo movimento do corpo que se opera num espaço virtual, como ocorre no estado de transe ou de grande intensidade de criação artística. Isso aconteceria quando a consciência se deixa invadir pelos movimentos do corpo, afirmando que os dois elementos convergem, transformando-se. No caso de experiências como as do Contact Improvisation - que envolvem ais explicitamente o movimento dos corpos dos participantes em uma relação tátil, dialógica, de proposição e ação, de distribuição de peso no espaço e em relação com o outro, a ideia de comunicação entre corpos-consciência é claramente ilustrada, porém, seria possível uma transposição desse entendimento para relações menos dependentes de um contato tátil, como exemplificado por Gil (2001)?

A partir da teoria de Leibniz sobre as pequenas percepções, Gil (2005) aponta alguns níveis de percepção: um primeiro nível remeteria a forças ma-

6. Sugiro o entendimento de comunicação a partir de sua etimologia, termo latino communicare significa partilhar, participar de algo, tornar comum (COMUNICAÇÃO, s.d.), diferentemente da comunicação enquanto "transmissão de informação entre um emissor e um receptor que descodifica (interpreta) uma determinada mensagem" (Idem). 
croscópicas e à representação, o que implica também as pequenas percepções, que define a força como um invisível visível capaz de fazer que o próprio olhar sofra transformações. As pequenas percepções seriam caracterizadas pela ausência de consciência de si, mas podem ser percebidas de modo confuso quanto a suas partes, e mais claramente em seu conjunto. Há também um tipo de pequenas percepções, apresentadas por esse autor, que formam as macropercepções e asseguram a passagem entre duas macropercepções. Gil (2005) observa que a análise de Leibniz dedicada às pequenas percepções as colocaria em um espaço de diferença de escala, o que deixaria de distingui-las da percepção comum. Gil ressalta, então, o nascimento das pequenas percepções, como no deslocamento de dois contextos, o que seria como a possibilidade de identificar hipocrisia escondida em um sorriso, por exemplo, afirmando que a diferença interna gerada nas pequenas percepções dissolve-se entre dois contextos, um habitual, tornado virtual, e outro novo, tornado atual. A atmosfera, feita de micropercepções, seria resultante de investimento de afeto, que implicaria em uma abertura dos corpos. Inerentemente a essa abertura à atmosfera, há um processo de osmose que quebra barreiras entre interior e exterior, corpo e coisas e corpos e corpos. Essa característica da atmosfera é que se mostra diferente do que pode ser redutível a um conjunto de relações de signos, que seria semiotizável, conforme afirma Gil. A atmosfera é, para ele, infra-semiótica, e ele afirma, ainda, que haveria uma pré-disposição, uma semiabertura do corpo nesse contexto relacional da atmosfera, e esse processo de osmose mostraria a quase-inscrição dos afetos nas coisas e nos corpos, o que pressupõe a criação de um meio entre as coisas e os corpos, caracterizando a atmosfera como área. A osmose produziria um devir-forma-intensivo diante da capacidade de constituição e reconstituição da atmosfera e o deslocamento entre o trivial e o não trivial.

Tomando como ponto de partida a ideia de relação de forças intensivas, já observada na teoria de Gilles Deleuze (2009) acerca da percepção da obra de arte, é possível chegarmos à análise de outros modos de relação entre proposição artística presencial e público, que não sejam somente vinculados a instâncias de representação e interpretação de significados, mas à possibilidades de consideração dos sentidos emergentes nessa relação entre corpos que se afetam mutuamente. Gil (2001) traz a afirmação de que a dança 
não precisa significar, e questiona como é possível que se compreenda o sentido do movimento dançado, uma vez que ele não opera em uma lógica de construção de sentido (leia-se significado) traduzível em uma linguagem articulada. Para Gil, o sentido ou a significação compreendem um horizonte, na acepção fenomenológica, o que também evoca presença de um modo implícito. Os gestos, despossuídos de sentido previamente definido, também podem ser percebidos em sua particularidade. Tendo em vista a questão da presença, de quanto uma abordagem fenomênica da arte evocaria as presenças do lugar, um convite ao desprendimento das certezas acerca da recepção na experiência artística parece claro. Um aspecto a ser observado é o fato de que, diante de uma composição performativa que considera os acontecimentos no aqui-agora, não seria o artista o detentor do saber sobre os efeitos de seu trabalho, uma vez que ele se baseia em seus afetos e suas percepções de eficácia. Estaríamos tratando, quiçá, de deixar a cargo da configuração relacional momentânea do encontro, a emergência das potências afetivas nos corpos, nas "presenças" do lugar. Uma noção de presença impositiva, aurática, cheia de expressividade já não seria mais tão adequada a esse contexto. Fischer-Lichte (2011) faz um paralelo entre as abordagens do corpo fenomênico e do corpo semiótico direcionando uma discussão acerca da presença que considera o ambiente. Para ela,

a presença não é uma qualidade expressiva, e sim puramente performativa. Gera-se por meio de processos específicos de corporização que o ator engendra em seu corpo fenomênico ao ponto de dominar o espaço e prender a atenção dos espectadores (FISCHER-LICHTE 2011, p. 197, tradução minha).

Talvez, a responsabilidade do artista já não se trate mais de "dominar" o espaço e a atenção do outro, mas de convidar as presenças do lugar a partilharem essa experiência, instigando-os com suas ações, a construir a sua própria teia de sentidos acerca daquilo que vivencia. Suas ferramentas estariam mais próximas de uma abertura às emergências do encontro, do que ao treinamento para se conquistar um corpo dilatado, e talvez impávido, incapaz de escutar o entorno, de perceber as ações e reações do seu interlocutor. A pesquisadora teatral francesa Béatrice Picon-Vallin (2008) relaciona 
a eficácia à abertura às relações entre o artista e o ambiente, com um dizer do corpo em constante devir. As medidas prévias dessa relação só poderiam conter as próprias impressões de afeto do artista, de quem desenhou a proposição relacional, e que pode apenas deduzir as impressões do trabalho artístico nos outros corpos.Gil (2005) questiona: se não é o significado, o que apreenderia quem observa os gestos abstratos? Para ele, o corpo e suas funções seriam capazes de tecer sentidos com o mundo de um modo único, só por eles apreensíveis. Assim, os movimentos corporais já conteriam em si sua significação completa. Nesse contexto, Gil apresenta alguns indicadores de intensidade de vida que se aproximam da acepção espinosista de conatus (ESPINOSA, 1992), expondo a teoria do psicólogo e psicanalista Daniel Stern sobre a existência dos afetos de vitalidade e dos afetos categoriais. A diferença entre os afetos de vitalidade e os categoriais é exposta por Gil da seguinte forma: os afetos de vitalidade se apresentariam no recém-nascido, indicando uma potência de vida que acompanharia o indivíduo durante toda sua existência, e seriam uma experiência mais abstrata do que a experiência dos atos que acompanham os afetos categoriais, que seriam, por sua vez, uma intensidade de vida, como a alegria, tristeza, medo, cólera, repulsa, surpresa. Para Gil, os movimentos dos afetos de vitalidade não seriam nem discretos nem macroscópicos, mas microscópicos e contínuos. Segundo esse autor, ambos os modos de afeto partilham os modelos de descarga dos neurônios, apesar de pertencerem a territórios diferentes do sistema nervoso. $\mathrm{O}$ afeto de vitalidade seria, para Gil, um acesso à qualidade do que é sentido, quando acontecem essas espécies de transformações, esses modos de afeto nos permitiriam compreender imediatamente os afetos categoriais - macroscópicos e discretos -, o que faria aumentar ou diminuir imediatamente nossa potência de agir, considerando essa capacidade de compreensão que temos. Gil afirma que, se entendidos por esse aspecto, os gestos e os movimentos não precisariam ser explicados, pois já conteriam em si o dispositivo capaz de decifrá-lo. O afeto seria, então, uma força que possui seu sentido implícito.

Ao questionar o tipo de apreensão de quem olha os movimentos não significativos do bailarino, Gil chega às unidades de sentido extra-proposicional, que seriam os movimentos de transição e os movimentos do inconsciente de posição. A ideia de signo se dissolveria no corpo-em-movimento. Embora 
haja a possibilidade de transformação das unidades de sentido em quase-signos, Gil afirma que, o que a dança faz é absorver os signos corporais e dissolvê-los, configurando o gesto do sentido. Nesse contexto, o espectador não veria a significação, mas moveria-se como o bailarino, em um movimento que preexiste a absorção de signo para remeter-se a si próprio. O espectador entraria na imanência do sentido do movimento dançado ao recebê-lo com seu corpo inteiro. O que faz Gil (2001, p. 120) afirmar que "se não compreendemos a dança, é porque ela não foi feita para ser compreendida". Os movimentos de transição, assim como os do inconsciente de posição que, segundo Gil, configurariam o núcleo dos movimentos dançados, tendem ora para o gesto signo, ora para a forma pura das forças, cujos sentidos se apresentariam sob a forma de nuvens.

Como já exposto, é inegável o fato de a produção artística se valer tanto da articulação de significados - para que se estabeleça alguma conexão inicial entre proposição e interlocutor -, quanto da exploração de formas intensivas, ao assumir a possibilidade da emergência de diferentes sentidos de modo individualizado. A questão a ser levantada nessa discussão é a necessidade de se desvincular da assertividade, do consenso que o significado poderia nos oferecer, como produtores de uma arte capaz de comunicar (no sentido de passar informação) para, em vez disso, assumir a necessidade da abertura a novos parâmetros desse fazer em movimento constante, que é a arte. O teatro e a dança, como artes da ação, do movimento, se mantêm em uma relação estreita, principalmente na contemporaneidade, em um processo de contaminação entre linguagens que parece inevitável.

A pesquisadora teatral Ileana Diéguez (2014, p. 128) apresenta um ponto de vista sobre a impossibilidade de uma essencialidade, uma pureza na arte contemporânea, que, segundo afirma, "reconhece-se hoje como uma estrutura de acontecimento, de situações, de práticas in situ (site specific), de teatralidades, de performatividades e (re)presentacões", o que, para Diéguez, está atendendo a uma demanda da própria vida, com uma teatralidade em campo expandido, que parece já não caber "nas caixas pretas do teatro".

Ao tratarmos das artes da presença, em que o corpo é meio, coisa e também acontecimento, nos aproximamos de um desejo de criar potência de afeto na relação entre as presenças do ambiente. A potência de afeto seria, 
nesses termos, a possibilidade de chegar a um momento, a um instante em que algo nos provoca a ponto de nos mobilizar, de provocar fissuras perceptivas, de revirar nosso ponto de vista. A arte ganhou esta séria responsabilidade: a de nos fazer estranhar o mundo, vivê-lo de outros modos que não somente pelos da automação cotidiana, o que parece adequado a um contexto de produção capitalista. Assumindo essa tarefa, e reagindo a formas preestabelecidas diversas, o artista parece surfar nas ondas de um mar revolto, que exige a cada segundo uma nova configuração, o que impediria, por exemplo, a manutenção de planos e desejos prévios, e de lugares de observação (e de ação) privilegiados. Termos como escuta, porosidade, e emergências relacionais são recorrentes nesse contexto das artes da presença, que passam a produzir intensidades de afeto no aqui e agora, na relação "entre" corpos.

\section{Referências bibliográficas}

COMUNICAÇÃO. Significados. s.d. Disponível em: <http://www.significados.com.br/ comunicacao/>. Acesso em: 13 maio 2016.

DELEUZE, G. Diferença e repetição. Rio de Janeiro: Graal, 2009.

DESGRANGES, F. A inversão da olhadela: alterações no ato do espectador teatral. São Paulo: Hucitec, 2012.

DIÉGUEZ, I. Um teatro sem teatro: a teatralidade como campo expandido. Tradução Eli Borges. Sala Preta, São Paulo, v. 14, n. 1, p. 125-129, 2014. Disponível em: <http://www.revistas.usp.br/salapreta/article/view/81758/85340>. Acesso em: 12 maio 2016.

ESPINOSA, B. Parte II: da natureza e da origem da alma. In: Ética. Lisboa: Relógio d’Água, 1992.

Parte III: da origem e da natureza das afecções. In: Ética. Lisboa: Relógio d’Água, 1992.

FISCHER-LICHTE, E. Estética de lo performativo. Tradução Diana González Martín e David Martínez Perucha. Madrid: Abada, 2011.

GIL, J. N. O gesto e o sentido. In: Movimento total: o corpo e a dança. Tradução Miguel Serras Pereira. Lisboa: Relógio d’Água, 2001. p. 103-130.

Abrir o corpo. In: FONSECA, T.; ENGELMAN, S. Corpo, arte e clínica. Porto Alegre: UFRGS, 2004.

Pequenas percepções. In: LINS, D. (Org). Razão nômade. Rio de Janeiro: Forense, 2005. p. 19-32.

GUMBRECHT, H. U. Produção de presença: o que o sentido não consegue transmitir. Rio de Janeiro: Contraponto/PUC-Rio, 2010. 
KASTRUP, V. A aprendizagem da atenção na cognição inventiva. Psicologia \& Sociedade, Rio de Janeiro, v. 16, n. 3, p. 7-16, set./dez. 2004. Disponível em: <http:// www.scielo.br/pdf/psoc/v16n3/a02v16n3.pdf>. Acesso em: 12 maio 2016.

Cognição inventiva, arte e corpo. In: CONGRESSO DA ABRACE, 8., 2014, Belo Horizonte. Anais do VIII Congresso da Abrace, Belo Horizonte: EBA/ UFMG, 2014.

DUENHA, M. L. Presença e(m) relação: a potência do afeto no entre corpos. 2014. Dissertação (Mestrado em Teatro) - Centro das Artes, Universidade do Estado de Santa Catarina, Florianópolis, 2014.

DE MARINIS, M. Corpo e corporeidade no teatro: da semiótica às neurociências pequeno glossário interdisciplinar. Revista Brasileira de Estudos da Presença, Porto Alegre, v. 2, n. 1, p. 42-61, jan./jun. 2012. Disponível em: <http://seer.ufrgs.br/ index.php/presenca/article/view/24243/18213>. Acesso em: 13 jun. 2012.

En busca del actor y del espectador: Compreender el teatro II. Buenos Aires: Galerna, 2005.

O'SULLIVAN, S. La estética del afecto: pensar el arte mas allá de la representacion.

Exitbook - Revista de Libros de Arte y Cultura Visual, Madri, n. 15, p. 8-21, verão 2011.

PICON-VALLIN, B. A cena em ensaios. Tradução Fátima Saadi, Cláudia Fares e Eloisa Araújo Ribeiro. São Paulo: Perspectiva, 2008.

RANCIĖRE, J. A partilha do sensível: estética e política. Tradução Mônica Costa Netto. São Paulo: Editora 34, 2005.

O espectador emancipado. Tradução Daniele Ávila. Urdimento, Florianópolis, v. 1, n. 15, p. 107-122, out. 2010.

Recebido em 01/01/2016

Aprovado em 10/05/2016

Publicado em 30/06/2016 